\title{
NOTE
}

\section{A dinoflagellate-like parasite in Alaskan spot shrimp Pandalus platyceros and pink shrimp P. borealis}

\author{
Theodore R. Meyers ${ }^{1}$, Donald V. Lightner ${ }^{2}$, Rita M. Redman ${ }^{2}$ \\ 'Alaska Department of Fish and Game, Commercial Fisheries Management and Development Division, PO Box 25526. \\ Juneau, Alaska 99802, USA \\ ${ }^{2}$ University of Arizona, Department of Veterinary Science, Tuscon, Arizona 85721, USA
}

\begin{abstract}
Similar dinoflagellate-like organisms were observed histologically in spot shrimp Pandalus platyceros and pink shrimp $P$. borealis from Yakutat and Prince William Sound, Alaska, USA, respectively. Infection in spot shrimp caused chalky white musculature, described as 'milky' by local fishers. Ultrastructurally, the organism in the spot shrimp differed morphologically from the bitter-crab-syndrome dinoflagellate described for Alaskan Tanner crabs Chionoecetes bairdi and C. opilio, and Hematodinium perezi described from various crab species in marine waters off Europe and the southeastern United States. Our results suggest that the agent is undescribed and infects 2 species of pandalid shrimp.
\end{abstract}

KEY WORDS: Shrimp - Dinoflagellate $\cdot$ Parasite

Commercial fishers have reported a longstanding occurrence of 'milky' shrimp harvested around Yakutat, Alaska, USA. Undocumented reports were that up to $50 \%$ shrimp within a given pot could have chalky white muscle tissue, but that prevalences were commonly less than $1 \%$ in a particular area. Affected shrimp were observed most frequently in gear set at shallow depths of 18 to $27 \mathrm{~m}$. Milky shrimp were observed primarily in January and February but sometimes as early as December if colder weather occurred earlier. Affected shrimp are said to virtually disappear by May.

A similar white muscle condition known as 'cotton shrimp' is caused by many different species of microsporidian protozoa (Sindermann 1971, 1990). However, morphological evidence indicates that the agent discussed in this paper is probably a dinoflagellate and that it occurs in 2 shrimp species from at least 2 locations in Alaska.

Materials and methods. Samples of adult shrimp were received from 2 general locations (Fig. 1). The first sample consisted of 4 specimens of spot shrimp Pandalus platyceros, collected in commercial pots on December 26, 1989, from waters off the southwest shore of Knight Island near Yakutat, Alaska. These shrimp weighed approximately $43 \mathrm{~g}$ each, were fixed in $10 \%$ unbuffered formalin and consisted of 2 grossly normal specimens and 2 shrimp with the milky condition. The remaining samples consisted of 11 sets each of 20 spot shrimp (mean weight each of $13.7 \mathrm{~g}$ ) and 1 set of 19 pink shrimp $P$. borealis (mean weight each of $2.75 \mathrm{~g}$ ) collected from several oiled and unoiled sites in Prince William Sound (PWS), Alaska, during the spring and summer of 1989, in the aftermath of the 'Exxon Valdez' oil spill. These shrimp were fixed in neutral buffered formalin but otherwise preserved as outlined by Bell \& Lightner (1988). The PWS samples were part of oil spill assessment studies reported on in more detail elsewhere (unpubl. report, March 6, 1992, for contract No. IHP-91-037, D. V. Lightner \& R. M. Redman, University of Arizona, Tuscon, AZ, USA).

One apparently normal and one abnormal shrimp from the Yakutat sample were processed for histologi-

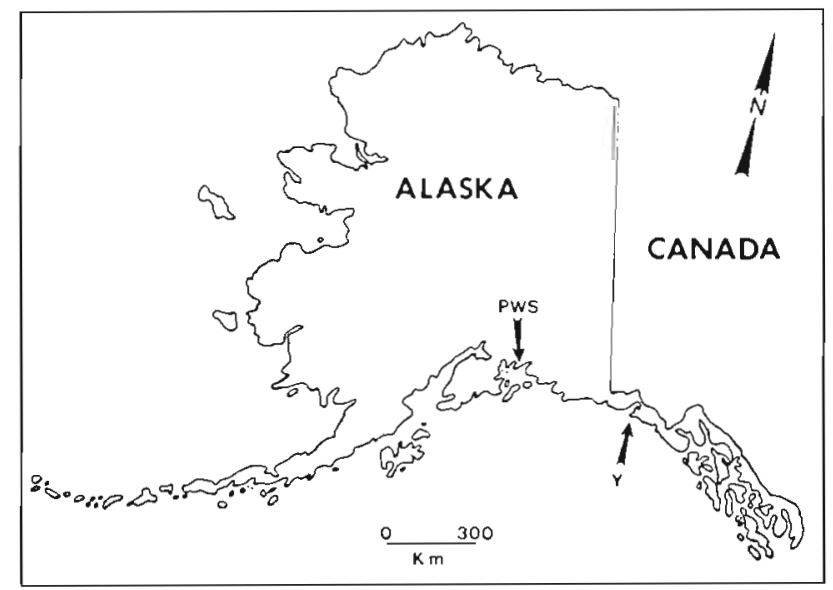

Fig. 1. Locations in Alaska where spot shrimp Pandalus platyceros and pink shrimp P. borealis were collected. PWS: Prince William Sound; Y: Yakutat 


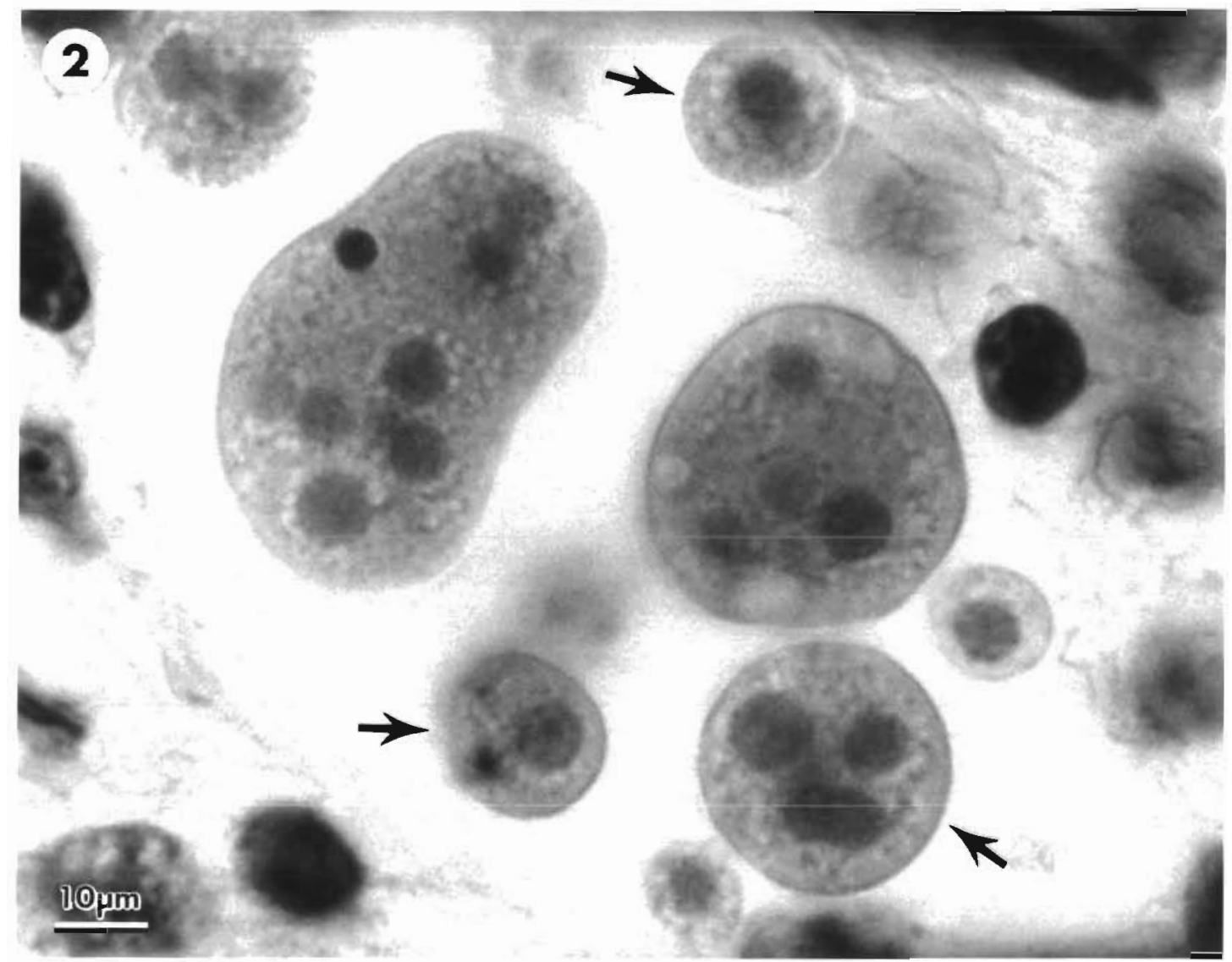

Fig. 2. Pandalus platyceros. Uninucleate and multinucleate dinoflagellate-like organisms in the connective tissues. Hematoxylin and eosin, $\times 1187$

cal examination by embedding major organs in paraffin using standard procedures including hematoxylin and eosin (H\&E) staining. Fluids from the fixed tissues of both normal and affected shrimp were smeared on glass slides, air-dried and stained with Diff Quik (Meyers et al. 1987). Ten representative spot shrimp from each of the PWS sample sets and all 19 of the pink shrimp were processed for histology using H\&E stain as described by Bell \& Lightner (1988).

Fluids collected from fixed tissues of the affected Yakutat shrimp were centrifuged at $2500 \times g$ for 5 min and the pellet post-fixed in $1 \%$ osmic acid in $0.1 \mathrm{~m}$ cacodylate buffer (ph 7.2). A $1 \mathrm{~mm}^{2}$ portion of hepatopancreas was similarly post-fixed and both were processed for standard transmission electron microscopy (TEM) using Spurr's resin and uranyl acetate and lead citrate stains. Thin sections were examined on a Philips EM 300 TEM operated at $60 \mathrm{kV}$.

Results and discussion. The preserved milky spot shrimp from Yakutat exhibited white tail musculature that was chalky in texture and a cloudy fluid could be expressed from the cut surfaces of these tissues and the viscera. Stained smears of this fluid in Diff Quik showed large numbers of a single-celled round organism having a 'bulls-eye' appearance due to a large well-defined centrally located nucleus. Histological examination of tissues from the same shrimp showed myriads of the organism, which measured about 14 to $20 \mu \mathrm{m}$ in diameter, throughout all tissues examined. Cytoplasm of the parasite was lightly eosinophilic and the nucleus was again sharp in profile with no dinokaryotic figures observed (Fig, 2). Occasionally larger multinucleate forms were present (Figs. 2 \& 3). The only host pathology visible was vacuolar degeneration and thinning of digestive tubular epithelium of the hepatopancreas when compared to the apparently normal spot shrimp processed in parallel. In the normal shrimp, no single-celled organisms were observed in either Diff Quik smears or in the tissues examined histologically.

A similar if not identical organism was observed in 2 of the 19 pink shrimp from PWS that were examined histologically. One individual was heavily parasitized as above (Fig. 3) while the other had a low grade infection by the organism most easily observed as cell clus- 


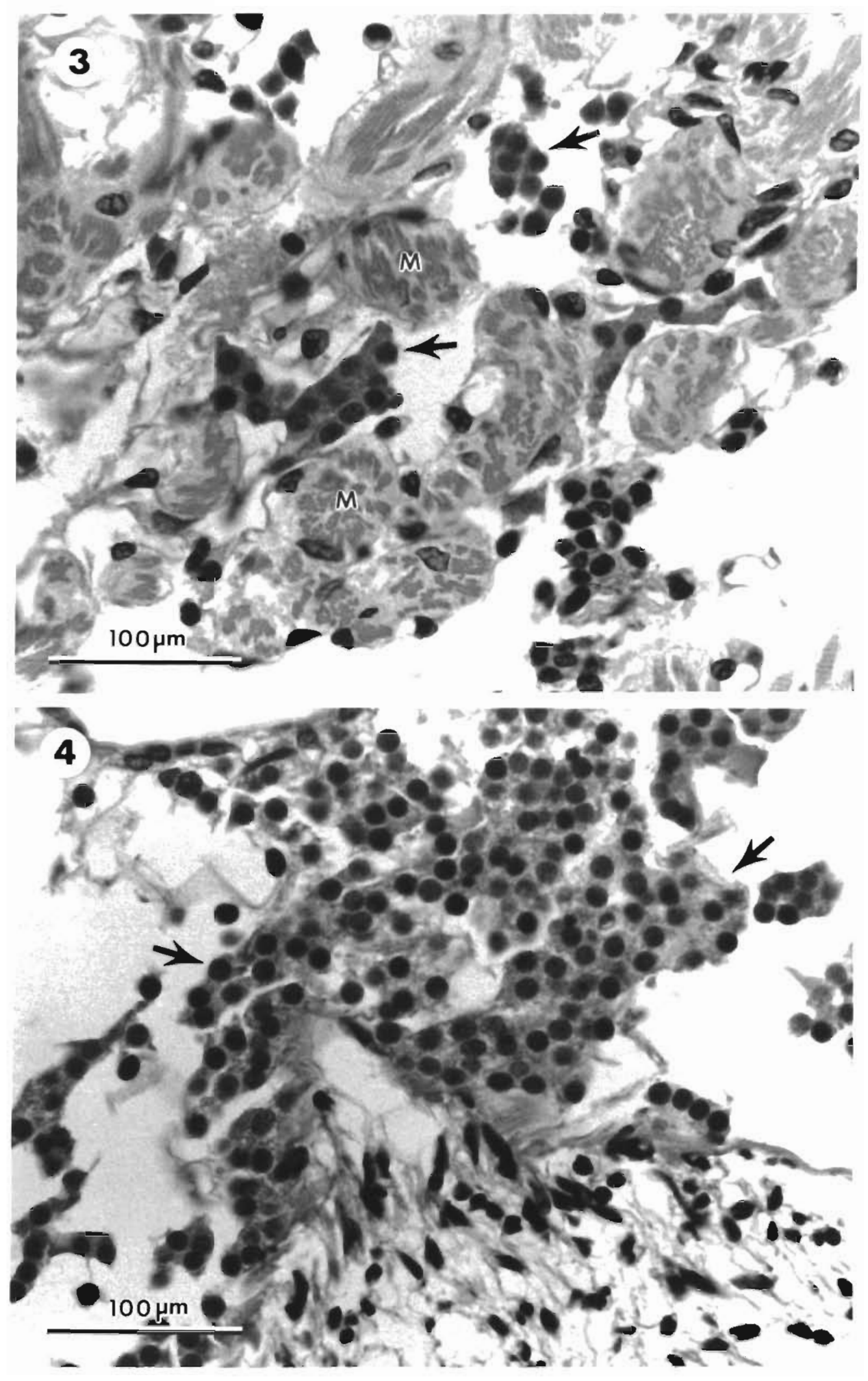

Figs. 3. \& 4. Pandalus borealis tissues parasitized by dinoflagellate-like organisms (arrows). Hematoxylin and eosin, $\times 310$ Fig. 3. Organisms between muscle bundles (M) of the heart. Fig. 4. Organisms within the hemocoel at the base of a periopod 


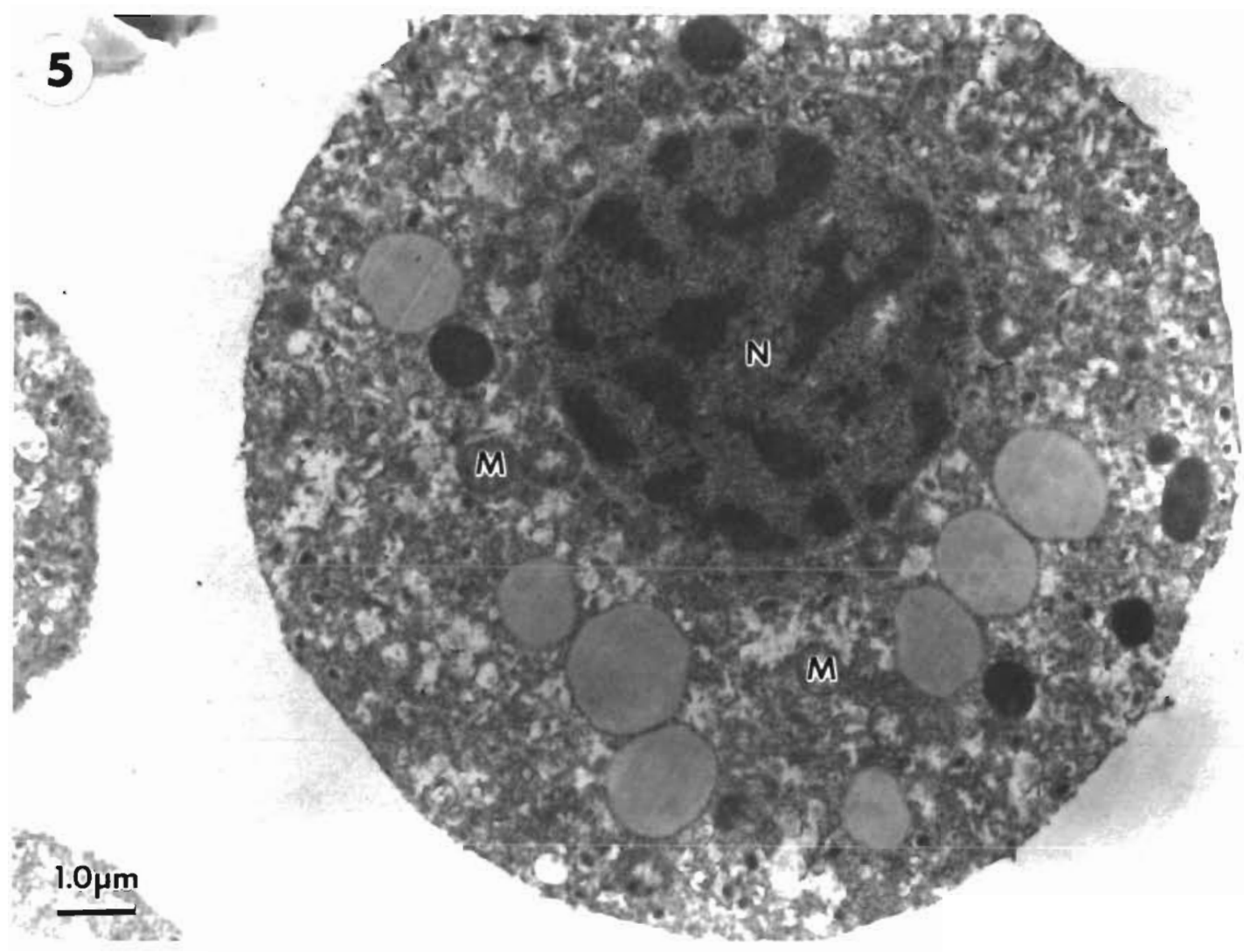

Fig. 5. Transmission electron micrograph of a dinoflagellate-like organism from fixed tissue fluids showing a centrally located round nucleus ( $N$ ) and abundant cytoplasm with mitochondria (M). Uranyl acetate and lead citrate, $\times 9820$

ters in the hemocoel around the ventral nerve cord and in the ventral sinus (Fig. 4) The parasite was not observed in the 110 spot shrimp from PWS that were examined histologically.

Ultrastructural examination of pelleted material and hepatopancreas tissue from the parasitized Yakutat spot shrimp showed the same rounded organism. Its round nucleus contained electron-dense chromatin surrounded by a distinct nuclear envelope. The abundant cytoplasm contained numerous large mitochondria, vacuoles and lipid-like inclusions, but no trichocysts (Fig. 5). Unidentified, small, membrane-bounded inclusions, each containing a structure resembling a coiled spring, were abundant throughout the cytoplasm and immediately beneath the cell surface (Figs. $6 \& 7$ ). Frequent breaks present in the plasma membrane may have been fixation artefacts.

The milky condition reported in the spot shrimp was caused by a unicellular parasite in the hemolymph which, based on light microscopy, appeared to be the same organism observed histologically in the pink shrimp from PWS.

The shrimp parasite was tentatively identified as the vegetative stage of a dinoflagellate based on: its vascular rather than histozoic invasion of the host, its size and unicellular appearance, its plasmodial forms, and its lack of haplosporosomes unique to potentially similar looking haplosporidian protozoa (Perkins 1968). However, the typical dinokaryotic nuclear detail unique to dinoflagellates could not be demonstrated either. The organism was quite different from the bitter-crab-syndrome (BCS) dinoflagellate described in Alaskan Tanner crabs Chionoecetes bairdi and C. opilio (Meyers et al. 1987, 1990, Meyers 1990). Most notably as indicated above, the shrimp parasite did not have the dinokaryotic nucleus with $5 \mathrm{~V}$-shaped chromosomes which is common in the BCS agent. Ultrastructural examination showed that the distinct

Figs. 6 \& 7. Samples from Pandalus platyceros. Uranyl acetate and lead citrate. Fig. 6. Higher magnification of a dinoflagellatelike parasite showing a clearly defined nuclear envelope (arrow), mitochondria (M) with poorly preserved cristae, lipid-like inclusions (L) and abundant membrane-bounded unidentified organelles (*), $\times 50000$. Fig. 7 Unidentified organelles (*) in Fig. 6. $\times 132400$ 


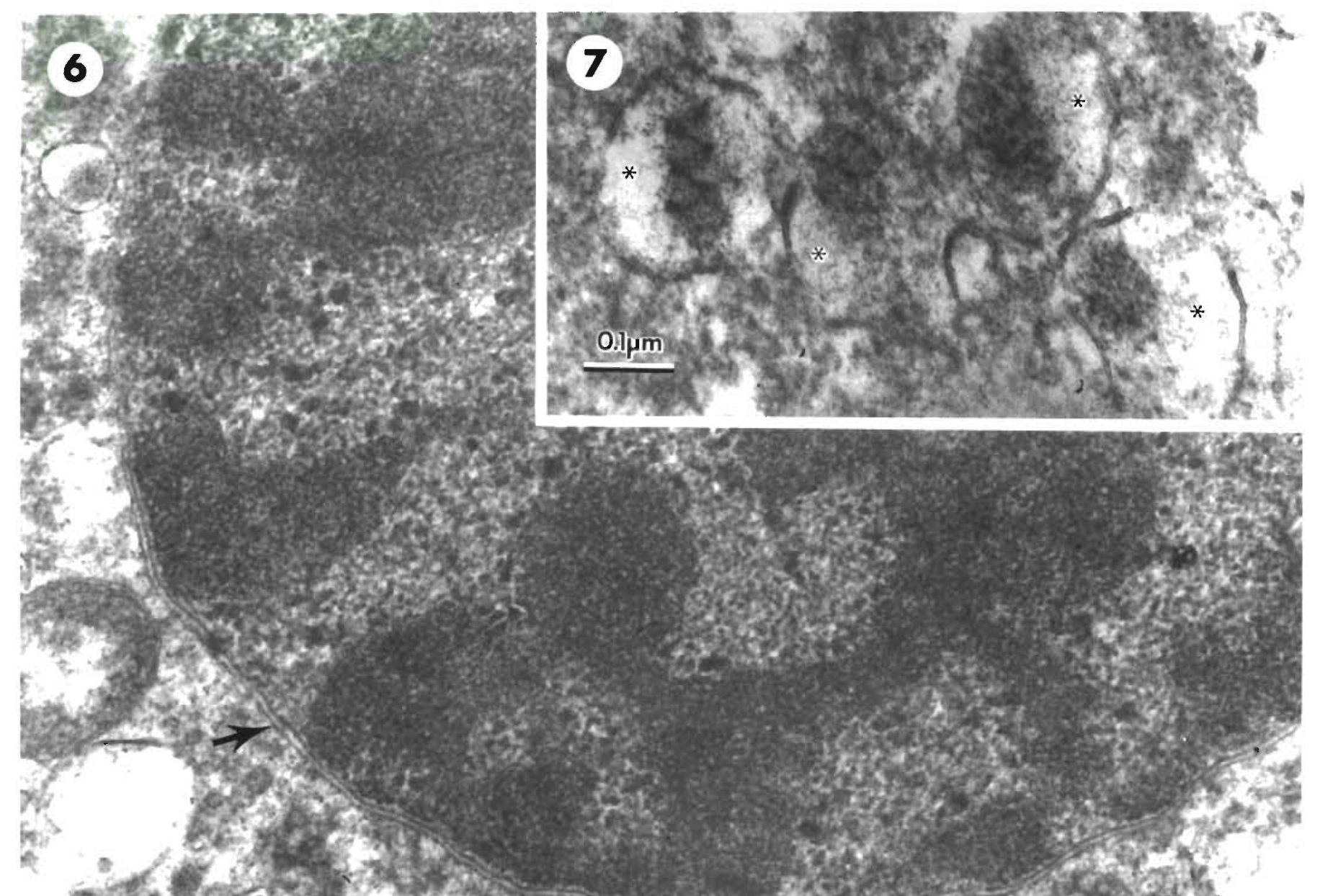

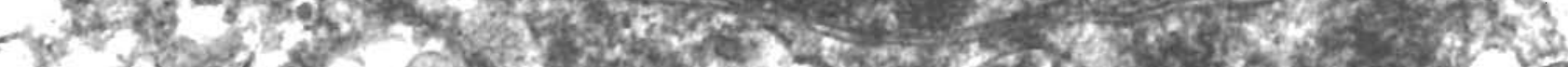
r.t. gra

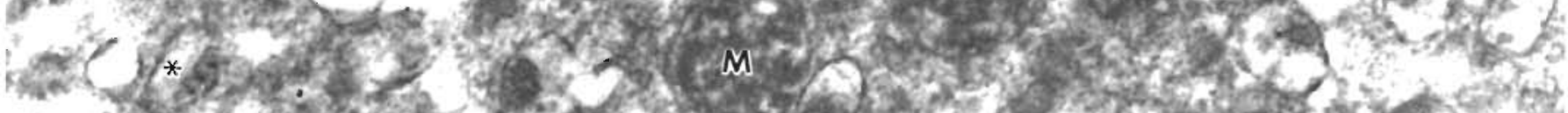

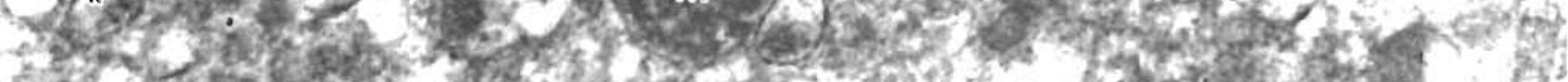

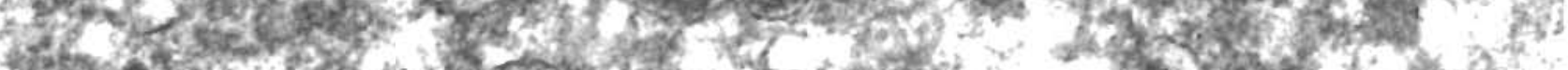

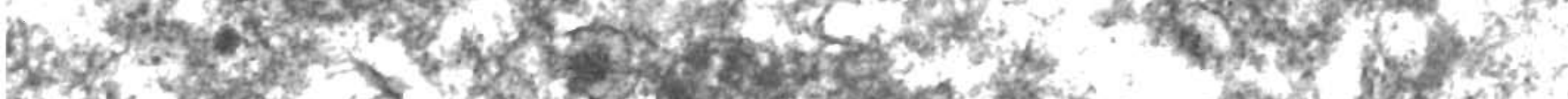
2.

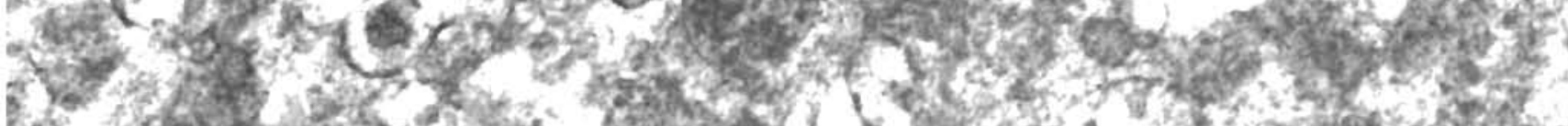
E.

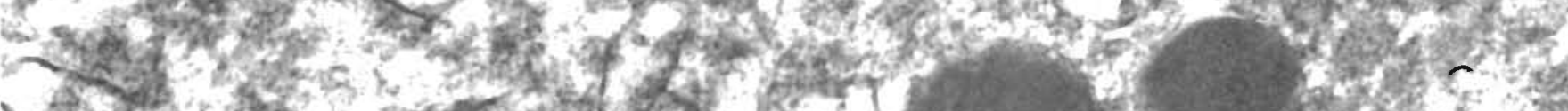

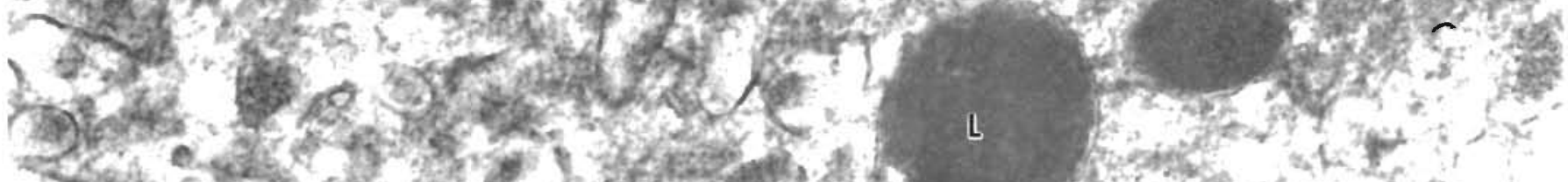

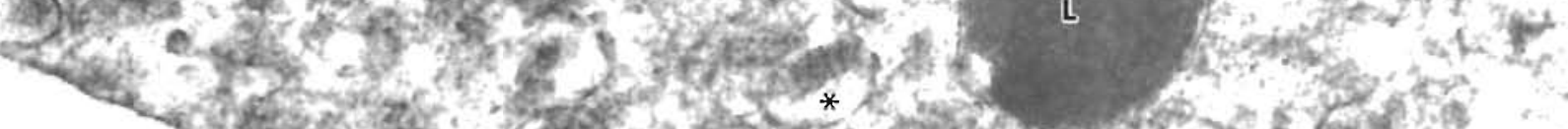
0.5 m

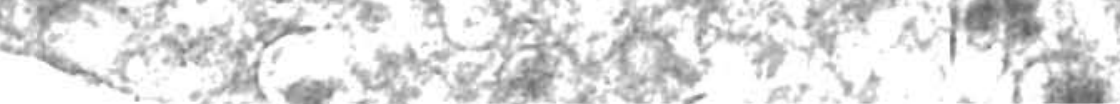


nuclear profile seen with light microscopy was due to a well-defined nuclear envelope. The nucleus was also more centrally located, round, and contained less defined clumps of chromatin. In contrast, the nucleus of the BCS parasite is very eccentric, has a less defined nuclear margin and has very electron-dense, whorled or beaded chromatin that often causes irregular bulging of the nuclear profile (Meyers et al. 1987). The cytoplasm of the shrimp agent contained many mitochondria and other organelles as well as numerous unidentified membrane-bounded inclusions. Abundant cytoplasmic organelles are not visible in the BCS parasite due to huge homogeneous inclusions that occupy most of the cytoplasmic space. The smaller unidentified inclusions in the shrimp parasite also were not observed in the BCS parasite nor reported in Hematodinium perezi, another dinoflagellate described from several decapod crustacean hosts from Europe (Chatton \& Poisson 1931) and the southeast coast of the United States (Newman \& Johnson 1975, MacLean \& Ruddell 1978, Couch 1983). This shrimp parasite also lacked trichocysts in the cytoplasm which is a major ultrastructural difference from $H$. perezi. The BCS agent also has trichocysts, but only in the biflagellated spore stages (Meyers et al. 1987). No flagella were apparent in the shrimp parasite to indicate that it was a motile spore form.

The only other dinoflagellate-like parasite reported from shrimp is a peridinean that occurs in eggs of the pink shrimp Pandalus borealis from the Gulf of Maine (Stickney 1978) and the Gulf of Alaska (Holmes et al. 1980). This parasite is described to produce fine networks of 2 types of multinucleate plasmodia within the egg yolk, each giving rise to a morphologically distinct zoospore. Replacement of host material by zoospores causes rupture of parasitized eggs (Sparks 1985). Apparently the peridinean is found only in extruded eggs and does not produce nonmotile vegetative stages. A relationship between this parasite and the agent described here is unlikely but a definitive comparison awaits further investigation.

Except for our limited data, the distribution and prevalence of this parasite in pandalid shrimp species are still undocumented. There was mention that a Hematodinium-like protozoan, possibly the same as the one described here, was observed in 1 to $2 \%$ of pandalids from the coast of British Columbia, Canada (unpublished 9--11 December, 1992, report from the Fish Disease Commission of the International Office of Epizootics, Paris). Further details were not given. A hematodinium-like protozoan has recently been reported in spot prawns Pandalus platyceros by S. M. Bower \& J.
A. Boutillier (abstract), 1993 National Shellfish Association, 85th neeting in Portland, Oregon, USA.

Extensive infection by this parasite is probably fatal to shrimp hosts but the condition may not be particularly important in those populations where the prevalence remains low

Acknowledgements. This study was funded in part by contract No. IHP-91-037 for Oil Spill Assessment Studies in Prince William Sound through the Alaska Department of Fish and Game (ADF\&G), Anchorage and in part by the ADF\&G Commercial Fisheries Management and Development Division, Juneau.

\section{LITERATURE CITED}

Bell, T. A., Lightner, D. V. (1988). A handbook of normal shrimp histology. Special Publication No. 1. World Aquaculture Society, Baton Rouge

Chatton, E., Poisson, R. (1931). Sur l'existence, dans le sang des crabs, de peridiniens parasites Hematodinium perezi n. g., n. sp. (Syndinidae). C. r. Soc. Biol. 105: 553-557

Couch, J. A. (1983). Diseases caused by protozoa. In: Bliss, D. E. (ed.-in-chief) The biology of Crustacea, Vol. 6. Provenzano, A. J. (ed.) Pathobiology. Academic Press, New York, p. 79-111

Holmes, P. B., Mueller, G. J., Hauck, A. K. (1980). Observations and speculations on premature egg loss in Gulf of Alaska Pandalus borealis (pink shrimp) Soc. Invertebr. Pathol. XIII Ann. Meet., Seattle (abstract)

MacLean, S. A., Ruddell, C. L. (1978). Three new crustacean hosts for the parasitic dinoflagellate Hematodinium perezi (Dinoflagellata: Syndinidae). J. Parasitol. 64: 158-160

Meyers, T R. (1990). Diseases of crustacea: Diseases due to protistans and metazoans. In: Kinne, $O$. (ed.) Diseases of marine animals, Vol. III. Biologische Anstalt Helgoland, Hamburg, p. 350-389

Meyers, T. R., Koeneman, T. M., Botelho, C., Short, S. (1987) Bitter crab disease: a fatal dinoflagellate infection and marketing problem for Alaskan Tanner crabs Chionoecetes bairdi. Dis. aquat. Org. 3: 195-216

Meyers, T R., Botelho, C., Koeneman, I M., Short, S. Imamura, K. (1990). Distribution of bitter crab dinoflagellate syndrome in southeast Alaskan Tanner crabs Chionoecetes bairdi. Dis. aquat. Org. 9: 37-43

Newman, N. W., Johnson, C. A. (1975). A disease of blue crabs (Callinectes sapidus) caused by a parasitic dinoflagellate, Hematodinium sp. J. Parasitol. 61: 554-557

Perkins, F. O. (1968). Fine structure of the oyster pathogen Minchinia nelsoni (Haplosporida: Haplosporidiidae). J. Invert. Pathol. 10: 287-305

Sindermann, C. J. (1971). Internal defenses of Crustacea: a review. Fish. Bull. U.S. 69: 455-489

Sindermann, C. J. (1990). Principal diseases of marine fish and shellfish. Vol. 2, Diseases of marine shellfish. Academic Press, Inc., New York

Sparks, A. K. (1985). Synopsis of invertebrate pathology exclusive of insects. Elsevier, New York

Stickney, A. P. (1978). A previously unreported peridinian parasite in the eggs of the northern shrimp, Pandalus borealis. J. Invertebr. Pathol. 32: 212-215 